Journal of

Sociology

\title{
Cancer care decision-making and treatment consent: An observational study of patients' and clinicians' rights
}

\begin{tabular}{|c|l|}
\hline Journal: & Journal of Sociology \\
\hline Manuscript ID & JOS-2016-102.R1 \\
\hline Manuscript Type: & Original Manuscript \\
\hline Keyword: & $\begin{array}{l}\text { decision-making, cancer care, observation study, epistemic rights, deontic } \\
\text { rights }\end{array}$ \\
\hline Abstract: & $\begin{array}{l}\text { This study identified ways in which patients and medical specialists } \\
\text { negotiated decisions about cancer treatment by observing decision-making } \\
\text { discussion in situ. Audio-recordings of cancer care consultations with 18 } \\
\text { patients, their support people, and their medical specialists including } \\
\text { medical oncologists, radiation oncologists and surgeons were collected in } \\
\text { different regions of New Zealand. Patients were followed-up with interviews } \\
\text { and specialists provided consultation debriefings. The interpretation of the } \\
\text { data drew on the concepts of epistemic and deontic rights to argue that in } \\
\text { complex consultations, such as occur in cancer care, we need to reconsider } \\
\text { the simple dichotomy of preferred consultations styles as paternalistic or } \\
\text { based on shared decision-making. Decision-making is a dynamic process } \\
\text { with specialists and patients linked into networks that impact on decision- } \\
\text { making and where rights to knowledge and rights to decision-making are } \\
\text { interactionally negotiated. The level of information and understanding that } \\
\text { patients desire to exercise rights needs to be reconsidered. }\end{array}$ \\
\hline \hline
\end{tabular}


Much research on cancer decision-making takes an individualistic psychological perspective focusing on cognitive and emotional processes and seeking ways to improve them in the consultation (Reyna et al. 2015). In medical sociology decision-making is embedded in analyses of medical dominance and power and how it is conceptualised has changed over time. Parsons' functionalist account, a paternalistic model, positions the patient as passive, where a legitimate sick role requires acquiescence to medical authority (Gerhardt 1987). Interactionist and ethnomethodological approaches highlight asymmetries in consultations between patients and clinicians but patients are also viewed as active agents in decisionmaking (Costello and Roberts 2001). Patient positioning in the medical encounter has been viewed in relation to Foucauldian influenced analyses of neo-liberal subjectivity whereby patients are made responsible for their healthcare decision making and cultural demands are made on them to be positive, strong willed and to choose to live (Broom 2017; Steinberg 2015). Other sociological analyses of the medical profession note the complex mix of developments such as the role of evidence-based medicine as potentially reinforcing medical dominance through its reductionist model, the role of medical uncertainty as challenging this dominance, or a shift where the medical profession can draw on indeterminacy in clinical practice to reconfigure its expertise (Broom and Adams 2010). This paper builds on these accounts and furthers our understanding of decision-making by observing points where decisions are actually made.

There has been much research exploring the possibilities of shared decision making (SDM) in healthcare. SDM is conceptualised as a scenario where both the clinician and the patient are involved in the decision-making process and information exchange (Pollard et al. 2015). Physicians and patients vary in their attitudes to SDM. In a review of patient barriers and facilitators to SDM, factors identified included patient characteristics (e.g. ethnicity), patient 
attitudes (e.g. a 'doctor knows best' attitude) and clinician characteristics (approachable or not). In order for patients to be involved in decision-making they need to be empowered, not just have the knowledge to participate (Joseph-Williams et al. 2014). A particular barrier to SDM is poor health of the patient (Joseph-Williams et al. 2014). Oncology physicians report positive attitudes to SDM and physicians in general are more supportive in scenarios where "they do not feel strongly about one treatment alternative" (Pollard et al. 2015: 1053). That is, in a scenario of clinical equipoise where clinical benefit does not clearly outweigh harm SDM is particularly important as patient preferences and values are critical. Alternatively, where guidelines or recommendations about treatment exist physicians are likely to feel pressure to make those recommendations (Reyna et al. 2015).

Researchers suggest that it is important to understand the mechanisms of decision-making in order to develop interventions to improve decision support (Reyna et al. 2015) and that descriptive work be undertaken to map out the elements of doctor and patient involvement in decision-making (Gattellari et al. 2001). This paper provides insight into the mechanisms of decision-making in cancer care consultations by identifying the elements of epistemic and deontic rights and their interplay.

The research reported here is based on recordings of cancer care consultations. From initial observation of the data it was clear that the consultations involved complex negotiations around who had the right to know and who had the right to decide, and these varied according to a range of circumstances. To better identify how these rights to know and decide are manifested and negotiated in the consultation the concepts of epistemic and deontic rights were drawn on. By drawing on the concept of rights we argue that we can more precisely 
identify when and how health professional and patient agency play out in the consultation. The research provides empirical detail to debates in the sociological literature about responsibilization, neo-liberal subjectivity and medical dominance, linking these to the literature on SDM.

Epistemics refers to knowledge claims "that interactants register, assert, and defend in and through turns of talk and sequences of interaction" (Heritage 2013: 555). In interactions participants have a different epistemic status and recognise their differences in knowledgeability and rights (Heritage 2013). For clinical knowledge the consultant has epistemic rights, but for the thoughts and feelings of the patient the patient has epistemic rights.

Whereas epistemic authority relates to knowing, deontic authority relates to courses of action. Recommendations and informing are based on epistemics and decisions are based on deontics (Lindström and Weatherall 2015). Typically in a consultation the clinician has epistemic authority and rights in relation to medical knowledge and practice. This puts the clinician in what Heritage refers to as the $\mathrm{K}+$ position on an epistemic gradient and the patient in a $\mathrm{K}$ position. Informing can move the patient up the gradient. A clinician might also claim deontic authority and rights to decide on what action is to be taken. Alternatively the patient may have deontic authority. Lindström and Weatherall (2015: 49) argue that "patients have the ultimate deontic right to reject medical expertise and authority", but they may "relinquish their deontic rights by deferring to the doctor's authority" (2015: 41).

Epistemic rights can be positioned in different ways to provide patients with more or less agency. There is as yet limited sociological exploration of epistemic and deontic rights. 
Toerien and colleagues observed 13 consultations between neurologists and patients noting a difference between a recommendation, where knowledge about what may be done is combined with a view on what should be done, and option-listing, where the knowledge of the options is claimed by the neurologist but not necessarily a view on which one should be selected (Toerien et al. 2013). Pilnick and Zayts (2016) suggest, on the basis of an analysis of antenatal screening consultations, that professionals take a particular epistemic stance, which they term unknowing, which is based in a non-directive ethos. Unknowing is applied in situations where options are available for antenatal testing but clinicians avoid recommending an option as, for them, the decision should be based on the feelings of the pregnant women. The worry or concern of the women is not something to which clinicians have epistemic access. The analysis presented below builds on these insights by drawing on both deontic and epistemic rights demonstrating the dynamic nature of rights to know and do and their embedding in networks that extend out beyond the consultation room.

\section{Data and Methods}

This research was part of a multiple-phased research program that used qualitative methods to explore the cancer care journey of patients and how aspects of healthcare delivery may lead to inequitable outcomes for Māori (the indigenous population of Aotearoa New Zealand). Approval for the study was granted by the New Zealand Central region Ethics Committee. For this phase of the research 18 patient participants and eight specialists were recruited through clinical networks in four Aotearoa/New Zealand hospitals. Sampling was purposive to acquire a heterogenous sample to maximise opportunities to observe different issues being discussed and how they were responded to. Patients were included from a range of ages (adults $\geq 18$ years), ethnicities (Māori and New Zealand European), gender, cancer 
types, with and without comorbidities who had recently received a cancer diagnosis (or high likelihood of this in the case of lung cancer) and were about to discuss their treatment options. Patients' whānau (family) were present in most consultations and cancer nurse specialists were present in some. Specialists who agreed to participate identified possible patient participants who were contacted by the researchers and received verbal and written study information and asked to give written consent. The participating clinicians were two radiation oncologists, four medical oncologists and two surgeons. The cancers that were discussed in the consultations were breast (5), lung (4), prostate (2), bowel (2), rectal (1), stomach (1), testicular (1), skin (1), and abdominal sarcoma (1).

The digitally recorded consultations were between 24 and 71 minutes in length. Following the consultation patients were interviewed in private hospital rooms using a semi-structured conversational format to explore in detail their consultation, perception of the specialist, treatment, comorbidities and decision-making. Digitally recorded interviews were between 12 and 57 minutes in length. Specialists self-recorded answers to 12 questions postconsultation reflecting on the consultation, patient, comorbidity, communication and factors influencing decision-making. All recordings were transcribed and field notes were made.

For the analysis XX read all the transcripts through twice, inductively coding the data to themes and making extensive notes. Particular attention was paid to the unfolding of the interactions in the consultations, and this was achieved by providing a narrative overview for each consultation. YY and ZZ read the transcripts. Emerging themes and interpretations were discussed in team meetings. For this article the analysis focuses on the points in the interaction where decisions about treatment were being made. As the interpretation developed the concepts of deontic and epistemic rights were drawn on to illuminate the decision-making 
process. The content of the communication between the clinician and patient was then examined deductively to identify the epistemic and deontic claims, and discursive features such as mitigation and emphasis were noted in relation to those claims. In the following, patient participants are identified by pseudonyms and specialists by their area of expertise e.g. surgeon, oncologist.

\section{Findings}

Findings have been organised into two sections. The first provides a typology of recommendations in relation to epistemic and deontic rights. Three consultant decisionmaking modes are explicated - outright recommendation, favoured recommendation and open decision. In these modes the consultant clearly makes a recommendation or not, and by using epistemic and deontic rights we can see what aspect of decision-making is made available to patients. The second section, titled "rights beyond the health professional-patient dyad", considers two other important elements of decision-making - preconsultation deontics and the epistemic rights of others who may not even be at the consultation.

\section{Typology of recommendations}

\section{Outright recommendation}

In the outright recommendation the clinician presents the case in absolute terms, providing little opportunity for patient participation in the decision-making. This is akin to what Collins et al (2005) refer to as unilateral formats. In one-third of the consultations there are examples of decision-making that can be classified as outright recommendations, and in each 
consultation there is a different clinician. The recommendation for hormone therapy in the consultation with Susan illustrates this mode.

Susan is a 67-year-old New Zealand European with breast cancer who is attending a medical oncology consultation with her husband. In this consultation the female oncologist provides a detailed outline of the clinical effectiveness of treatment and states "you and I will talk about chemotherapy benefit, but the hormonal therapy I will myself tie you down and force it down your throat ((chuckles)).” The oncologist goes on to describe findings from pathology that followed surgery: "it tells me that at least a proportion of your cancer was thinking about being evil." This personification of the cancer is reinforced by an earlier statement where the oncologist refers to the cancer as "learning how to do something" in relation to spreading to the nodes. After describing the pathology the oncologist states "so you've got a nice... standard breast cancer, that we've got a lot of experience with and we know what to do with". This clearly establishes the grounds for a recommendation.

The oncologist outlines risks of side effects from the two possible drugs, ending this part of the consultation by stating that the drug being used can be changed if necessary but " $\mathrm{I}$ 'd rather you were on one of them". The oncologist concludes by saying that the hormonal therapy is "half as good again as surgery". Susan strongly aligns with the recommendation. In the post-consultation interview she states that she felt that the options were "very clearly my choice". Although this seemed to be the case with chemotherapy, discussed later, it is less apparent in relation to hormonal therapy.

A number of features can be noted. The clinician's emphatic recommendation about hormone therapy has multiple meanings. It is humorous in that the clinician would never actually tie 
the patient down, and the humour may be aimed at reducing anxiety and the interpersonal gap between clinician and patient (Wender 1996). It is also indicative of the strength of the clinician's views on the clinical benefits of the treatment. Cancer cells are represented as thinking, planning entities that have to be outwitted by modern medicine, but again in a lighthearted fashion. As the cancer is presented as one they know how to deal with there is then little to debate. This exchange is one of reassurance for the patient, with research indicating that indeed this is a desirable outcome of cancer care consultations (Gattellari et al. 2001) and has been described as a ubiquitous feature of outpatient cancer care consultations (Stark et al. 2001).The recommendation is made before any discussion of side effects. Finally, the decision-making process is not finalised in that there can still be on-going options to swap medications if desired. Throughout the discussion of hormonal treatment the oncologist has retained deontic rights to decision-making and the recommendation is clear and uncontested.

Gaining support from other practitioners can be drawn on in an outright recommendation. In discussing hormone treatment with Mary, a 59 -year-old New Zealand European who has breast cancer, the medical oncologist asks if the surgeon said anything about that, to which she says the surgeon told her that it "would be good to go with the hormone treatment". The oncologist responds with "Good. And that's exactly right...my recommendation definitely". A strong recommendation is built up by first ascertaining support from a previous practitioner.

Another feature of the outright recommendation is the downplaying of risks and side effects. Michael is a 58-year-old New Zealand European who is consulting a colorectal surgeon about a rectal tumour. After discussing the pathology and conducting an examination the surgeon states "number one, your rectum needs to come out. You've got the tumour there. You know 
that", to which Michael says "yes". Later the surgeon explains that after treatment and before surgery she will "specifically talk in more detail about potential complications". The complications to be talked about are a process of informing but not part of the decisionmaking process.

In Anika's consultation a narrative with a pre-determined plot can be observed. Anika is Māori and 32-years-old. The clinician notes that after the test results come back "we'll make a determination on whether or not you need Herceptin" and that "breast cancer in general is treated with up to four different types of therapy: surgery, chemotherapy, radiation, and hormone therapy". When she explains chemotherapy the oncologist states "recommended chemotherapy in you is a combination of three drugs". After explaining the process of giving one drug the oncologist states "at the end of that, we then transition to a medicine called Docetaxel. It's given either by itself, or if your tumour shows that there is HER2 positivity, I would add on Herceptin with the Docetaxel". The oncologist positions herself as having deontic authority on the basis of a pre-determined process, where guidelines may need to be followed (Reyna et al. 2015) and authority is embedded within the "precision" medicine and protocol-driven environment of current hospital-based breast cancer care (Day et al. 2017).

A common feature of all these cases is that there is perceived to be a clear treatment pathway for which the clinical benefits substantially outweigh the risks. Clinicians' assumptions of deontic rights can be understood in this context.

Favoured recommendation 
In the favoured recommendation clinicians build a case for an option, claiming epistemic rights, but the possibility of an alternative is available to patients providing them with deontic rights. Collins et al (2005) refer to a bilateral approach that involves patient communication that aligns with this recommendation, but also with the open decision category discussed below. Again one-third of consultations contained examples that could be classified as a favoured recommendation. The example of Christine illustrates this mode.

Christine is a 50-year-old New Zealand European attending a radiation oncology consultation about an inoperable lung tumour. Any decision is made from the perspective that treatment has a chance of prolonging life and easing symptoms, but not of cure. The oncologist describes the pathology then states that "this is inoperable". He briefly outlines the mechanisms of chemotherapy before saying "I think if we can do that for you now, it'd be the best thing". A clear recommendation has been made, and this is prior to any discussion of side effects or discussion of specific benefits. Following this the oncologist mentions side effects from chemotherapy in a very general way: "It can cause nausea...can make you more prone to infections or bruises or bleeding", concluding with "so it is balancing out how much benefit it might give you against what side effects it will give you".

The oncologist further qualifies the issue of balance, saying that chemotherapy "works fantastically well for some people" but "does nothing for others". He moves on to discuss another option, radiotherapy, which in this instance "works pretty reliably, but only on the bits we can aim at to target". In response to Christine asking about the likely success of chemotherapy the oncologist says "about thirty percent, so not huge" and the "chances of radiotherapy helping the cough and the pain are more likely sixty percent" but he immediately follows this with "this is advanced cancer, and nothing is going to eradicate it". 
The oncologist says that without treatment "it could number your days in months" and "with successful treatment, that doesn't necessarily give you years and years, but it can usually give you many more months". After querying from Christine the oncologist says "some people get a few years out of it but they're in a small minority. But someone's got to be a small minority". Throughout this consultation bad news is mitigated or softened by the oncologist. At the end Christine clearly and emphatically makes her decision with "we go for everything we can, fight the bastard, fight till the end". Christine's determination aligns with powerful cancer culture imperative to 'choose to live' at any cost (Steinberg 2015).

Noticeable in Christine's consultation is that a recommendation is made, but both the clinical benefits and disadvantages of treatment are presented in a mitigated way. The patient is given an opportunity to consider the balance and decide whether to accept the recommendation or not. Different features of a favoured recommendation can be observed in other consultations. In some cases the favoured recommendation occurs where the cancer is deemed incurable. Tehimana, a 74-year-old Māori man who has incurable stomach cancer, is given an option of radiotherapy treatment to try to stop the cancer ulcer bleeding so that he can go back on Warfarin, which he had been taking due to having had strokes. The decision he participates in is not about treating the cancer per se, but treating the cancer to deal with the co-morbidity of stroke.

In some consultations the patient declines deontic rights because of limited epistemic access. Dave, who is 83 , states that "it's not fair you telling me that I should say either one, two, or three. Because I'm not the expert... what do you think would be the best outcome for me?" Dave resists a customer role where he is required to make choices, but wants to be a patient 
following expert advice (Glasdam et al. 2015). Because Dave is "not the expert" he does not have epistemic access, and without epistemic access it is unfair to position him with deontic rights as the decision-maker. In response to this challenge the oncologist eventually makes an explicit recommendation: "to really try and hit it hard, without damaging too much lung".

In the chemotherapy discussion phase with Susan we see another feature with her asking what the clinician would do. The medical oncologist responds that she would "do absolutely everything". A variation is a clinician personalising the situation to indicate the favoured recommendation. Rona, a Māori woman with breast cancer, is told in relation to Herceptin that "if you were my sister, that's what I'd want you to have."

Provisional plans can support favoured recommendations. Rona stated that she wants to "get going" with treatment but she also expressed strong reservations about having a likely recommendation of Herceptin treatment as "we've got a family full of dicky hearts". Rona has expressed epistemic access to knowledge about side effects and the experience of her family, but has signalled that this will not influence her decision to "get going". In response to this ambivalent presentation the oncologist suggests that options are open and "we don't have to decide anything today" but she will still "make a provisional booking" stating that "if we start...things are allowed to change".

\author{
An additional feature of Rona's consultation is the presentation of information. The \\ oncologist has asked in what format Rona wants information - facts and figures or more \\ general. This is not common across the dataset, but the choice of how to deliver information \\ on risks and benefits can be consequential. In Rona's case having a general level of informing \\ gave the oncologist the opportunity to conceal certain information that was likely to be
}


distressing. The oncologist states in her debrief that they did not reveal "that there is still a reasonable chance that the cancer could come back". In this case it was unlikely to impact upon the actual decision as Rona clearly states at the start that her intention is to follow the medical recommendations. In this example a clear recommendation is made and some potentially distressing information is withheld, indicating that the oncologist has retained epistemic rights on these matters. Rona's expression of concern has, however, been responded to by the oncologist in that she continually provides Rona with the deontic right of refusal.

A common feature of favoured recommendations is that there are options that the patient can consider. Clinicians have strategies available to present recommendations without overriding patients' deontic rights, such as provisional bookings and mitigating bad news. Patients have strategies available to justify their stance, such as appealing to a lack of epistemic access.

\section{Open decision}

The open decision illustrates a particular complexity of decision-making in cases where clinical outcomes are in balance or are difficult to determine. The clinician provides information without making a clear recommendation. Moana's consultation illustrates an open decision that is difficult to make with high risk and high levels of uncertainty. She is a 62-year-old Māori who is attending a radiation oncology consultation with a nurse as a support person. There is uncertainty about the diagnosis as there is X-ray evidence of a likely lung tumour but because of her comorbidity (severe COPD) a biopsy or operation is discounted. In addition, radiation therapy may cause further damage to the lungs. Moana has severely reduced activities because of breathlessness. After a lengthy discussion about the 
clinical benefits and risks of the treatment the oncologist says you "don't have to make that decision today". He does not make a recommendation but provides Moana with a complex set of figures: $80-90$ percent chance of it being cancer; without treatment unlikely to survive for three years; she has 30 percent lung capacity and treatment would lead to loss of a further 2-3 percent; a 30 percent chance that radiation treatment will lead to more shortness of breath due to lung irritation; a 70 percent chance that radiation therapy will eradicate the tumour; uncertainty about whether the COPD would get worse or not; if the tumour gets bigger "I don't think radiation would be helpful". Moana is required to weigh up this complex information.

The support person asks, "if you take away that two to three percent (of lung capacity), would she be confined to like basically resting most of the day" and the oncologist says "that's the worry". He relates this to "quality of life" to which Moana says "there's none, absolutely nil". Moana moves to an 'interim decision' to talk to her daughters and to try out an alternative approach: "apricot kernels, seeds... vitamins and all that sort of thing". She states that by the next appointment "I will have done a course of it, and we'll see where we are".

The interim measure of trying out something different is not challenged by the oncologist. In the face of clear uncertainty the oncologist takes the position of information provider and cedes the decision-making to Moana. Moana signals her intent to discuss treatment options with her daughters and decides to access a knowledge system that is different to the oncologist's.

In John's consultation an open decision is based on the relatively small clinical benefit. He is a 72-year-old New Zealand European with lung cancer who is attending a medical oncology 
consultation with his wife. The oncologist states that the surgical resection undertaken was successful but "there still is a risk of return" though chemotherapy can decrease that chance and

\author{
"I'm going to show you the stats on it ... my job is to teach you about it so that you \\ can make the decision that's right for you".
}

When the oncologist asks if there are questions John says "you just tell me what to do". The oncologist resists making a recommendation saying that "probably fifty to sixty percent of people" in John's situation "take me up on the offer" to have chemotherapy because "if the cancer comes back, I'm going to beat myself up saying maybe it wouldn't have if I'd done chemo". The presentation by the oncologist could suggest a preference for treatment, for example, she notes that the majority of her patients have treatment. However, towards the end of the consultation she says "I sense you feel pretty comfortable with your decision and (to) not do chemotherapy" to which John says "I've bloody had enough, you know ((laughs))." The oncologist suggests John think about it. As with Moana we see clear uncertainty and likely negative impacts of treatment.

Robert's consultation illustrates an open decision but with hints of a favoured recommendation. Robert is a 32-year-old New Zealand European with testicular cancer attending a medical oncology consultation with his wife. The oncologist notes in the consultation that the "cancer's been removed" but that "there's a risk it could return" and so "how should we manage the risk". He outlines the risk of recurrence of cancer (15 percent) and the treatment options are surveillance or chemotherapy with surveillance. He notes that “there's very little problem with this treatment". 


\begin{abstract}
After talk about side effects Robert asks "which would be the preferred option, would you think?" referring to surveillance and chemotherapy. The oncologist states that the strategies "can't be distinguished" and that the cure rate for both is very high. He goes on to say that "adjuvant chemotherapy... reduces the risk of the cancer coming back" and:
\end{abstract}

\author{
People sometimes say, "Well, what would you do?" And I'd guess what I'd say is, I \\ would probably have the chemotherapy.
}

\begin{abstract}
Without prompting, the oncologist has shown his preference by appealing to a question that others might ask him. He adds that "we believe there is true equipoise between these two... there isn't a medically preferred option yet".
\end{abstract}

Robert does not make an overt decision in the consultation but in the post-consultation interview he reveals that he has decided to have chemotherapy as he talked to an oncology nurse after the consultation who told him that it was a "no-brainer". His report of the oncology nurse's view contrasts with the "equipoise" position stated by the oncologist. The case of Robert is in contrast to Moana and John in that the specialist has reassured him that there is "very little problem" with the treatment but even without any treatment the prognosis is very good.

\begin{abstract}
Linda declines treatment. She is a 52-year-old New Zealand European with a sarcoma who is attending the consultation by herself. The oncologist provides an extensive discussion on the risk and clinical benefits of radiation therapy and appears to have an open approach to the decision-making, concluding with:
\end{abstract}


So we've got a treatment that we know in this situation reduces the chance of local regrowth of tumour. But at a price of some immediate reduction in your health and how you feel, and some risks of a more longer-term upset. What it cannot do, though, is protect against what the tumour might do, if it's going to do it, and that is, spread.

When the oncologist asks what her "thoughts" are Linda says "if it's going to present itself again, well then it presents itself again". The oncologist contests this position with "Oh, it's kind of fatalistic" and he then upgrades the clinical benefits of treatment with "people are cured of these things".

Linda responds with "I'm one not to take anything... I deal with things if I really have to". The oncologist concedes to her deontic authority saying "it's up to you to make up your mind", however he states that if future monitoring "shows something suspicious" then he would recommend removing any re-growth and "more strongly recommend trying to knock it out with radiation". The oncologist is signalling that her decision is not final. After initially ceding deontic rights to the patient he has now partially reclaimed them. A similar process has been observed in surgical consultations where a treatment recommendation has been rejected and to maintain the action a follow-up appointment is presented as a way of indicating that the decision-making phase is not terminated (Stubbe et al. 2016)

\begin{abstract}
A common feature of open decisions is that they occur in consultations where specialists present a scenario where there is a high level of uncertainty about the weight of clinical benefit versus the weight of risk of treatment.
\end{abstract}




\section{Rights beyond the health professional-patient dyad}

By examining the types of recommendations made we can identify under what circumstances rights are made available to patients in the consultation itself and between the patient and the health professional. But rights are exercised by other people and at points other than in the consultation. It is important to note these as what can appear as a decision negotiated in the consultation may be influenced and even determined by outside events.

In Peter's consultation there is a complex interplay between participants in the consultation and between different consultations. The patient appears to leave the decision to the consultant but it transpires to be a decision determined at a prior consultation. Peter is a $57-$ year-old New Zealand European with prostate cancer who is attending a radiation oncology consultation with his sister. In the consultation the oncologist notes two available options, "basically radiotherapy, or watching and waiting", and asks if Peter has "any sort of expectations". Peter says "pretty much just doing what I'm told". At this point Peter appears to be ceding deontic rights to the clinician in this consultation, however he then states "I saw the surgeon, he just basically said .... radiography's probably the way to go". The oncologist explains what radiation can do, noting the "uncertainty of the benefit of radiation" because it is not known if the cancer has spread or not but that "radiation is really the only potentially curative treatment that you have". He states that he is "a bit more aggressive" with younger patients but I "can't guarantee that it's going to actually work in the long term".

The oncologist displays a favoured recommendation with patient deontic rights. He asks the patient "which way are you leaning?" to which Peter says "I'll pretty much just do what I'm told". The oncologist resists the patient ceding the decision-making to him with "I prefer to 
give you all the information...I don't like making these decisions for the person". But Peter continues relinquishing decision-making with "the better off of the options is to just do what I'm told". Peter then talks about a friend who died from breast cancer who "didn't even attempt to fight it" and "had done it the wrong way". This displays his epistemic access to knowledge of bad outcomes when a no treatment option has been taken, but he still does not make an overt decision. Explicit agreement occurs near the end of the consultation when the oncologist states that there are no guarantees that "this adds anything to your survival" and "are you happy with that?" Peter says "where do I sign up?"

In the post-consultation interview Peter says that he had "pretty much made that [decision] even before I came here". He was prepped by a consultant and was able to see this particular practitioner who took an aggressive approach. However, there was an intricate process of negotiation where he appears to not want to own the decision but do what is recommended. His story about a friend dying suggests wanting to have treatment without explicitly stating it. The clinician is required to do interpretive work to decipher what the patient is likely to want. This case raises the issue of who is claiming deontic rights here, with the patient and clinician attempting to cede them. In effect the patient ceded rights to a surgeon in a prior consultation.

The case of Nick, a 67-year-old New Zealand European with bowel cancer, plays out in a very similar way. In the post-consultation interview Nick states when asked if he has made a decision about his options "I don't think there was any decision to be made" because his surgeon had told him that he needed radiotherapy before the surgery. Deontic rights were in effect ceded to the surgeon consulted earlier. Costello and Roberts note a contrasting case in an oncology consultation where a patient successfully resists a recommendation based on the advice provided by another clinician prior to the consultation (Costello and Roberts 2001) 
Tehimana raises the possibility of a different approach to treatment for his incurable stomach cancer. He says that after his heart attack he was "taking aspirin and all that" and it "ate all the inside" and so he went on Māori medication for three months "and I was healed". Tehimana is opening up the possibility of taking a different approach to the cancer, rather than a simple alignment with the radiation oncologist, even though he has deployed the rhetoric of "you're the expert". Tehimana is suggesting that he has epistemic access, through his past experience, to another possible approach but the oncologist does not cede deontic rights to him to pursue this option.

For Patricia, a 72-year-old with colon cancer, chemotherapy would postpone treatment for a circulatory problem, which is "quite a big thing" for her as the latter restricts her activities. The consultant makes a favoured recommendation in that choice is available to the patient, but the oncologist mitigates concerns about side effects, highlights concerns about "the chances that one or two little cells have got clever and escaped", notes that "we are dealing with a cancer that we want to, and can, cure", and provides a provisional booking for chemotherapy that can be cancelled. In addition to this Patricia's daughter claims epistemic rights as "my husband died from colon cancer" and he was not offered follow up chemotherapy "which is something I've always had a major issue with". Toward the end of the consultation the oncologist states that Patricia will be booked in for chemotherapy, which can be stopped "but...I'm getting the impression that you're reasonably keen". Her daughter responds with "Oh, she will be". Patricia is given some space to exert her deontic rights by the oncologist but her daughter claims epistemic rights as a consequence of having experienced the death of her husband from colon cancer. 
Mary's consultation has a mixture of decisions with an outright recommendation for hormone treatment, but the decision about chemotherapy is not straightforward. The oncologist discusses chemotherapy outlining the clinical benefits, with side effects being mentioned but not specifically discussed, then asks Mary what her "gut feeling" is. Mary, who is attending the consultation on her own, replies with "I don't want it to come back". She goes on to say:

It's just too much of an interruption in my life ... it's interrupted my children's lives. Well my husband... had a heart attack on Christmas Day.

The role of Mary in the lives of her husband and children is drawn on in the decision-making. The oncologist reiterates that a decision about chemotherapy does not need to be made immediately with "I think you need to discuss it with other people". At this point other people are positioned as firmly involved in the decision-making. The oncologist then goes on with "I don't have a strong feeling about chemotherapy, but certainly if you want it you can have it". Mary responds with:

\begin{abstract}
it's not just a decision for me to make, either. It's a decision that my husband and I need to make together... and if it were to come back, I can tell you now, he'd be saying, "You should have had that." Because that's just him.
\end{abstract}

\begin{abstract}
At this point the oncologist retracts her earlier suggestion to involve "other people", saying in relation to Mary's husband "he's not the one that's sitting in the chair" and then "what we have talked about doesn't have to go, you know, out of the room in that sense". Deontic rights play out in a complex way here, with the oncologist ceding them initially to Mary and others that she should consult, but then becoming concerned that Mary is relinquishing her
\end{abstract}


rights to her husband. Mary then reveals that her husband's first wife died and "he just keeps saying to me, 'I'm not going through that"”. The oncologist responds with "oh gosh" and does not proffer any further advice on how Mary should make the decision. She then explains that "if you decided to have chemotherapy, but were really struggling, I would have a very low threshold to stop". In the post-consultation interview Mary states that she has not made a decision about chemotherapy.

\section{Discussion}

This research has found that it is common in cancer care consultations for clinicians to make outright and favoured recommendations, retaining epistemic authority and limiting the spaces for patients to exercise deontic rights. This finding aligns with paternalistic models of decision-making where patients have limited opportunities to enact agency and clinicians take responsibility for directing treatment plans, with treatment plans less negotiable in oncology settings compared to other settings (Costello and Roberts 2001).

Decision making, however, is not simply between the dyad of clinician and patient, but is distributed beyond the clinical encounter (Rapley 2008). Continuing attention needs to be paid to the social and interactional processes of consultations and their impact on decisionmaking. This research clearly identifies influences on decision-making from health professionals before or after consultations, from support people in consultations, and from significant others outside of consultations.

In these data clinicians could cede decision-making rights to the patient but appear to do so only in specific circumstances. It is the specificity of this ceding that reveals the extent and 
limits of patient-centred medicine and medical dominance in cancer care decision making, and the roles that uncertainty and indeterminacy play in the actual consultation

This research suggests that epistemic authority is rarely ceded, but deontic rights can be ceded to the patient in situations of clinical equipoise. Clinicians have the epistemic authority to determine if a scenario is one of clinical equipoise - not the patients. It has been suggested that a shared approach is most appropriate and most likely to occur in scenarios of clinical equipoise (Pollard et al. 2015). Joseph-Williams et al (2014) note that equipoise facilitates patient involvement in decision-making as in this situation patients may more clearly have permission to participate. We can suggest that in some instances this is more than facilitation but a situation that is imposed on patients, rather than simply being allowed.

Gattellari et al (2001) note that imposing choice may be detrimental if it does not align with the patient's desires and values and that those with poorer health status are least likely to want involvement in decision making. Our data suggest that poor health status in a state of clinical equipoise, perhaps the most difficult of situations for a patient, may be a likely situation where deontic rights are ceded by the doctor and in our dataset the one situation where epistemic rights were ceded. The responsible health care consumer is then an interactional achievement in the cancer care consultation where one form of medical paternalism is absent - the persuasion element we see in outright and favoured recommendations - but perhaps another form of medical paternalism is at play - where medical personnel foist responsibility on to inexpert patients. In situations where there is a significant epistemic gradient between practitioners and patients avoiding paternalism may not be an accessible option. 
If SDM requires equal epistemic access then SDM would be a rare event in the complex case of cancer consultations. As Reyna et al (2015) note there are cognitive issues, such as limits on being able to interpret figures and understand pathologies, and emotional issues, such as the dread and anxiety that can accompany cancer diagnoses, that arise in such consultations, that mean that decision-making is not as robust as might be desired. What we label as an 'open decision' here might conform to some of the ideals of SDM, but in these states of equipoise we can also read this as clinicians abandoning their role as decision-makers, which they exhibit elsewhere. We can note there that although medical professionals can draw on indeterminacy in clinical practice to reconfigure their expertise (Broom and Adams 2010), indeterminacy can also be used as in the example of clinical equipoise to require a form of patient expertise.

Outright, favoured or unilateral recommendations are made in situations where, from a clinical perspective, likely benefit is high and risk is low. Open decisions are most likely to occur at the two extremes of risk but where likely clinical benefit is low. At one extreme, there is high risk and limited benefit. At the other extreme low risk, but also low benefit. Arguably high risk situations are more likely to occur in the presence of co-morbidities, such as with Moana who has COPD, and any treatment may worsen an already difficult situation. Given that Māori are more likely to have co-morbidities (Sarfati et al. 2014) this data suggests that Māori may also be more likely to be required to make decisions in complex situations. This hypothesis could be explored further if bigger datasets of decision-making consultations were available. 
Ideals of SDM are not a norm in these cancer care consultations. Many aspects of SDM occur, but the ideals of sharing authority and the patient being able to comprehend the 'facts' are not easily met in the complex scenario of cancer treatment decision-making, a point well made in research on oncology specialists and nurses by Broom and Adams (2010). For many consultations treatment recommendations may have been considered prior to the consultation, very likely in multi-disciplinary team meetings (Dew et al. 2015). Clinicians are then primarily focused on informing the patient about the rationale for the decision and the treatment plan. Although patients may in theory have the deontic right of refusal, the massive epistemic gradient between the patient and the clinician with her clinical team means the concept of 'sharing' the decision is impractical. As Broom and Adams (2010) note, clinicians have to make judgments about a patient's desire to be involved in decision-making. What is prioritised in an emotionally intense consultation may not be shared decision-making, but may be dealing with the emotions and assuring the patient that something can be done.

There are possible ways forward that respond to some of the tensions in these consultations. In this data some clinicians attempt to ascertain whether patients prefer facts and figures or more general terms when discussing complex issues like treatment risks and benefits. The latter allows a more succinct summary but provides less detail for patient decision-making. There is a trade-off where the epistemic gradient between the patient and the clinician can either be narrowed or not. But this can be the patient's choice, where the patient chooses to be more or less informed. Potentially this could be extended even further, where the patient might be asked if they want to make the decision, or have a decision made for them. Rather than seeing the latter choice as one of paternalism, this could be viewed as a merciful response for patients in intolerable situations. This supports the concern raised by Pilnick and Zayts' (2016) that non-directiveness can be a burden for patients. Our argument supports 
their view that the dichotomy of consultations as paternalistic or based on SDM may require re-thinking (Pilnick and Zayts 2016). We could consider approaches to the cancer care consultation where patients are given the deontic right to decide what level of epistemic access they would like, and further, to decide whether they want the deontic right to be responsible for the cancer care treatment plan.

In this cancer consultation data the goal of more patient-centred approaches of patients having enhanced deontic rights can be seen to be quite circumscribed. Clinicians have a range of strategies to emphasise their epistemic authority and to offer few opportunities for patients to exercise deontic rights beyond agreement with their authority in situations where clinicians appear convinced of clinical benefit. Where clinical benefit is less clear, and there is a medical view of equipoise between clinical benefits and risks, clinicians are more likely to cede deontic authority, calling upon patients to take on responsibility for their own treatment paths. 
References

Broom, A. (2017) Suffering survivorship: Dilemma of survival, willful subjects, and the moral economy of dying, in A. Dragojlovic and A. Broom (eds), Bodies and suffering: emotions and relations of care. London and New York: Routledge.

Broom, A. and Adams, J. (2010) The reconfiguration of expertise in oncology: The practice of prediction and articulation of indeterminancy in medical consultations, Qualitative Health Research, 20, 10, 1433-1445.

Collins, S., Drew, P., Watt, I. and Entwistle, V. (2005) 'Unilateral' and 'bilateral' practitioner approaches in decision-making about treatment, Social Science \& Medicine, 61, 12, 26112627.

Costello, B. and Roberts, F. (2001) Medical recommendations as joint social practice, Health Communication, 13, 3, 241-260.

Day, S., Coombes, R.C., McGrath-Lone, L., Schoenborn, C. and Ward, H. (2017) Stratified, precision or personalised medicine? Cancer services in the 'real world' of a London hospital, Sociology of Health \& Illness, 39, 1, 143-158.

Dew, K., Stubbe, M., Signal, L., Stairmand, J., Dennett, E., Koea, J., Simpson, A., Sarfati, D., Cunningham, C., Batten, L., Ellison-Loschmann, L., Barton, J. and Holdaway, M. (2015) Cancer care decision making in multidisciplinary meetings, Qualitative Health Research, 25, 3, 397407.

Gattellari, M., Butow, P.N. and Tattersall, M.H.N. (2001) Sharing decisions in cancer care, Social Science \& Medicine, 52, 12, 1865-1878.

Gerhardt, U. (1987) Parsons, role theory, and health interaction, in G. Scambler (ed), Sociological theory and medical sociology. London and New York: Tavistock, pp. 110-133.

Glasdam, S., Oeye, C. and Thrysoee, L. (2015) Patient's participation in decision-making in the medical field - 'projectification' of patients in a neoliberal framed healthcare system, Nursing Philosophy, 16, 226-238.

Heritage, J. (2013) Action formation and its epistemic (and other) backgrounds, Discourse Studies, $15,5,551-578$.

Joseph-Williams, N., Elwyn, G. and Edwards, A. (2014) Knowledge is not power for patients: A systematic review and thematic synthesis of patient-reported barriers and facilitators to shared decision-making, Patient Education \& Counseling, 94, 291-309.

Lindström, A. and Weatherall, A. (2015) Orientations to epistemics and deontics in treatment discussions, Journal of Pragmatics, 78, 39-53.

Pilnick, A. and Zayts, O. (2016) Advice, authority and autonomy in shared decision-making in antenatal screening: the importance of context, Sociology of Health \& IIIness, 38, 3, 343359.

Pollard, S., Bansback, N. and Stirling, B. (2015) Physician attitudes toward shared decision making: A systematic review, Patient Education \& Counseling, 98, 1046-1057.

Rapley, T. (2008) Distributed decision making: the anatomy of decisions-in-action, Sociology of Health \& Illness, 30, 3, 429-444.

Reyna, V., Nelson, W., Han, P. and Pignone, M. (2015) Decision making and cancer, American Psychologist, 70, 2, 105-118.

Sarfati, D., Gurney, J., Stanley, J. and Koea, J. (2014) A retrospective cohort study of patients with stomach and liver cancers: the impact of comorbidity and ethnicity on cancer care and outcomes, BMC Cancer, 14, 821. 
Stark, D., Kiely, M., Smith, A., Morley, S., Selby, P. and House, A. (2001) Reassurance and the anxioius cancer patient, British Journal of Cancer, 91, 893-899.

Steinberg, D. (2015) The bad patient: estranged subjects of the cancer culture, Body and Society, 21, 3, 115-143.

Stubbe, M., White, S., Macdonald, L., Dowell, A., Gardner, R. and Dew, K. (2016) Do surgeons want to operate? Negotiating the treatment plan in surgical consultations, in $\mathrm{S}$. White and J. Cartmill (eds), Communication in surgical practice. Sheffield: Equinox, pp. 124-152.

Toerien, M., Shaw, R. and Reuber, M. (2013) Initiating decision-making in neurology consultations: 'recommending' versus 'option-listing' and the implications for medical authority, Sociology of Health \& IIIness, 35, 6, 873-890.

Wender, R. (1996) Humor in medicine, Primary Care, 23, 141-154. 